\title{
Manejo do atendimento odontológico durante a pandemia de Covid-19: o cirurgião-dentista frente à uma nova realidade
}

\section{Management of dental care during the Covid-19 pandemic: the dental surgeon in front of a new reality}

\section{Gestión de la atención dental durante la pandemia Covid-19: el cirujano dental frente a una nueva realidad}

\author{
Raquel Arantes Martins iD \\ Ana Paula de Almeida Nunes iD \\ Daniele da Costa Lourenço \\ iD \\ Rebeca Vidal Capelupi ${ }^{1}$ \\ Luciana Vidal Agra \\ Leonardo Santos Picinini ${ }^{2}$ \\ Rodrigo Guerra de Oliveira
}

1 bec641996@gmail.com

2 coapicinini@hotmail.com

Endereço para correspondência:

Raquel Arantes Martins

Rua Belo Horizonte, 243 - Apto. 202

São Mateus

36016-430 - Juiz de Fora - Minas Gerais - Brasil

E-mail: raquelarantes_95@yahoo.com.br

Recebido: 22.06 .2020

Modificado: 26.06.2020

Aceito: 21.08.2020

\section{RESUMO}

Através de uma revisão de literatura, a finalidade deste trabalho é analisar a pandemia de Covid-19, o estado atual em torno do vírus, esclarecer aos profissionais da área odontológica e discutir sobre os riscos e os cuidados que devem possuir durante a prática clínica. A maioria dos pacientes infectados apresentaram sintomas clínicos como febre, tosse seca, falta de ar e fadiga. A transmissão ocorre através de atividades respiratórias humanas, via contato direto com gotículas que podem ser inaladas ou atingirem as mucosas da boca, nariz ou olhos das pessoas que estão próximas. As práticas de atendimento odontológico invariavelmente sujeitam-se ao risco de infecção devido à natureza de seus procedimentos, os quais envolvem comunicação face a face com os pacientes, exposição frequente a saliva, sangue e outros fluidos corporais. É necessário prezar pela proteção, dos pacientes e toda sua equipe odontológica, buscando um ambiente seguro e que seguir as diretrizes orientadas.

PALAVRAS-CHAVE: Infecções por coronavírus. Odontologia. Controle de infecções. 


\begin{abstract}
Through a literature review, the purpose of this work is to analyze the Covid-19 pandemic, the current state around the virus, to clarify to dental professionals and to discuss the risks and care they should have during the clinical practice. Most infected patients had clinical symptoms such as fever, dry cough, shortness of breath and fatigue. Transmission occurs through human respiratory activities, via direct contact with droplets that can be inhaled or reach the mucous membranes of the mouth, nose or eyes of people who are nearby. Dental care practices are invariably subject to the risk of infection due to the nature of their procedures, which involve face-to-face communication with patients, frequent exposure to saliva, blood and other body fluids. It is necessary to care for the protection of patients and their entire dental team, seeking a safe environment and following the guidelines.
\end{abstract}

KEYWORDS: Coronavirus infections. Dentistry. Infection control.

\title{
RESUMEN
}

Através de una revisión de la literatura, el propósito de este trabajo es analizar la pandemia de Covid-19, el estado actual el virus, aclarar a los profesionales dentales y analizar los riesgos y la atención que deben tener durante la práctica clínica. La mayoría de los pacientes infectados tenían síntomas clínicos como fiebre, tos seca, falta de aliento y fatiga. La transmisión se produce a través de actividades respiratorias humanas, a través del contacto directo con gotitas que pueden inhalarse o llegar a las membranas mucosas de la boca, nariz u ojos de las personas cercanas. Las prácticas de atención dental están siempre sujetas al riesgo de infección debido a la naturaleza de sus procedimientos, que implican la comunicación cara a cara con los pacientes, la exposición frecuente a saliva, sangre y otros fluidos corporales. Es necesario cuidar la protección de los pacientes y todo su equipo dental, buscando un ambiente seguro y siguiendo las pautas.

PALABRAS CLAVE: Infecciones por coronavírus. Odontología. Control de infecciones. 


\section{INTRODUÇÃO}

A Covid-19 doença causada pelo vírus SARS-CoV-2, partiu de Wuhan, China, em dezembro de 2019 e tornou-se um grande problema de saúde pública, não apenas para China, mas também para todo o mundo ${ }^{1-2}$. A vigilância epidemiológica está sendo construída à medida que a OMS consolida as informações recebidas dos países e novas evidências técnicas e científicas são publicadas ${ }^{3}$. Atualmente a pandemia apresenta milhões de infectados pelo mundo e milhares de óbitos confirmados, com casos crescentes a cada iia $^{4}$.

O espectro clínico da infecção por coronavírus ainda não está definido. Até o momento, os sinais e sintomas clínicos são principalmente febre persistente de 3-4 dias, tosse seca, falta de ar e fadiga, e mais recentemente relatados, perda do paladar e olfato. Sintomas mais graves podem levar à Síndrome Respiratória Aguda Grave (SARS), arritmia, lesão cardíaca aguda, pneumonia, insuficiência renal, falência de órgãos, choque séptico, sendo necessário atendimento em unidade de cuidados intensivos e requerem terapia de oxigénio imediato ${ }^{4.9}$.

$O$ vírus pode ser fatal, principalmente entre pacientes com condições médicas pré-existentes, como doenças crônicas e doenças respiratórias ${ }^{7}$. Muitos casos vêm sendo relatados, alto risco de agravo pela condição de obesidade. A taxa total de mortalidade do Covid-19 já é estimada em $3.46 \%$ e a maioria dos pacientes $(80.9 \%)$ apresentou pneumonia assintomática ou leve, com base em dados publicados do Centro Chinês de Controle e Prevenção de Doenças ${ }^{9-10}$.

A transmissão entre humanos ocorre através de atividades respiratórias, via contato direto com gotículas, como falar, tossir, espirrar, podendo ser inaladas ou atingirem as mucosas da boca, nariz e olhos. Ou através do contato direto das mãos com superfícies ou objetos contaminados ${ }^{7-8,11}$.

As configurações de atendimento odontológico expõem cirurgiões-dentistas à microrganismos patogênicos, com risco de infecção pelo novo coronavírus, devido aos seus procedimentos, que envolvem comunicação próxima com os pacientes, exposição frequente a saliva, sangue e outros fluidos corporais, e o manuseio de instrumentos perfurocortantes ${ }^{12}$. A inalação de partículas e aerossóis no ar produzidos durante procedimentos odontológicos em pacientes com Covid-19, pode ser um procedimento de alto risco, onde dentistas são direta e indiretamente expostos a esse vírus ${ }^{8}$.

Portanto, como os cirurgiões-dentistas e suas equipes odontológicas estão expostos ao vírus, esses profissionais devem manter-se bem familiarizados com essa doença. Dessa forma, o presente trabalho visa realizar uma revisão de literatura sobre os cuidados necessários a um atendimento de excelência, buscando os cuidados para proteger a equipe, os pacientes e a comunidade da transmissão do Covid-19.

\section{REVISÃO DE LITERATURA}

Foi realizada pesquisa bibliográfica na base de dados MEDLINE (National Library of Medicine, USA - NLM), com as palavras-chave Covid-19 and dental practice, para critérios de inclusão artigos em suas versões completas e gratuitas, em língua portuguesa e inglesa. Além desses, também foram utilizados como referências os informes técnicos do Ministério da Saúde; Conselho Federal de Odontologia, Anvisa (GVIMS/GGTES/ANVISAN No4/2020).

\section{Biossegurança}

Durante todos os atendimentos é imprescindível a remoção de todos os adereços, como anéis, pulseiras, cordões, brincos e relógios ${ }^{13-14}$. Além disso, é necessária a utilização de luvas de procedimentos não cirúrgicos, gorro descartável, máscara cirúrgica, calçados fechados, protetor ocular, os óculos de grau não são considerados EPIs, pela sua precariedade em proteger lateralmente os olhos e jalecos fechados, estes itens devem ser usados por toda a equipe assistencial. Para o cirurgião-dentista e para o auxiliar é adicionado a estes itens o uso de capote descartável ou esterilizado, de mangas longas, punho de elástico e abertura posterior que deve ser usado fechado durante todos os procedimentos e protetor facial devem cobrir a frente e as laterais do rosto, ser de uso exclusivo para cada profissional, e após o uso, deve ser limpo e desinfetado com álcool $70 \% \%^{5,7,13}$.

Os EPIs e materiais infectados devem ser descartados em lixo apropriado enfatizando que as máscaras cirúrgicas devem ser retiradas pelo elástico, não sendo plausível colocá-las no pescoço ou bolsos ${ }^{7,13}$. Elas devem ser trocadas de 4 em 4 horas, pois sua capacidade de filtragem bacteriológica diminui com o tempo. Em procedimentos nos quais serão gerados aerossóis, a máscara que proporciona melhor proteção é a N95 ou PFF $2^{13}$.

Além desse cuidado em utilizar o EPI adequado, é necessária atenção dos profissionais ao retirar os equipamentos de proteção, devendo haver treinamento de toda a equipe de saúde. Para desparamentação, fazer a remoção da primeira luva de forma segura com a mão oposta, utilizando a parte externa para puxá-la, invertendoa para o avesso na retirada. Higienizar as mãos com álcool $70 \%$, por no mínimo 20 segundos, para dessa forma desamarrar o avental de forma segura para não levantar gotículas, retirá-lo ao avesso para desprezá-lo a cada paciente. Seguindo novamente pela higienização das mãos com preparação alcoólica, por no mínimo 20 segundos ${ }^{15}$.

O reforço para uma boa higiene das mãos é de grande importância, muito embora essa ação já seja pré-requisito de rotina para a prática odontológicas. É recomendável a lavagem criteriosa das mãos por 20 a 30 segundos com água 
e sabão, antes e depois do contato com qualquer pessoa ou após tocar em qualquer superfície. O dentista também deve lavar o rosto com água e sabão por 20 segundos após higiene das mãos e antes do atendimento odontológico ${ }^{7,14}$. Foi proposta uma Diretriz de Higiene das Mãos do departamento de controle de infecção do Hospital de Estomatologia da China Ocidental, Universidade de Sichuan, para reforçar a conformidade deste ato. De acordo com o estudo, a lavagem das mãos deve ser feita após tocar no paciente, mucosa oral, pele ou ferida danificada, fluido, sangue, secreção, excrementos, no ambiente e equipamentos sem desinfecção ${ }^{7}$. Considerando-se que a transmissão de infecção por gotículas no ar é considerada a principal via de disseminação, especialmente em clínicas odontológicas, todos os equipamentos de proteção individuais (EPIs) devem ser usados com ainda maior rigor ${ }^{7}$.

\section{Imunização do Profissional}

Pelo alto nível de exposição dos dentistas durante procedimentos odontológicos estes possuem um risco elevado de contrair doenças infecciosas, por isso é muito importante estarem imunizados. Como estratégia para diminuir a quantidade de pessoas com gripe, o Ministério da Saúde antecipou a Campanha Nacional de Vacinação contra a Influenza. A vacina não apresenta eficácia contra o Covid19, porém é uma ajuda para os profissionais de saúde descartarem as influenzas na triagem e acelerarem o diagnóstico para o Covid-19 ${ }^{13}$. Além disso, o cirurgiãodentista e sua equipe devem estar sujeitos a avaliações constantes de saúde, nas quais haja aferição da temperatura corporal duas vezes ao dia, sendo uma antes do início dos atendimentos e a outra ao longo do dia, devendo ser afastado por 14 dias o membro da equipe que apresentar febre ${ }^{7}$.

\section{Triagem do Paciente}

Os profissionais de odontologia devem ser capazes de identificar um caso suspeito de Covid-19 a partir de uma triagem inicial. Em um primeiro momento, a temperatura corporal do paciente deve ser medida através de um termômetro digital de testa, que prescinde de contato físico $^{15}$. Além disso, o dentista deve coletar um histórico médico do paciente através de um questionário (Figura 1).

Caso o paciente tenha respondido positivamente a um desses questionamentos, mas sua temperatura corporal estiver abaixo de $37.3^{\circ} \mathrm{C}$, o cirurgião-dentista tem a prerrogativa de adiar a consulta por 14 dias, instruindo o paciente a se isolar em casa e observar se haverá febre. Se, independente das respostas, o paciente apresentar febre, deverá ser posto em quarentena e não será atendido para procedimentos odontológicos, devendo ser encaminhado para cuidados e orientações médicas. E, por último, se responder não a todas as perguntas e estiver com temperatura corporal abaixo de $37.3^{\circ} \mathrm{C}$, o profissional poderá proceder com o atendimento odontológico, resguardando-se com medidas extras de proteção ${ }^{5,7,13-14,16}$ (Figura 1).

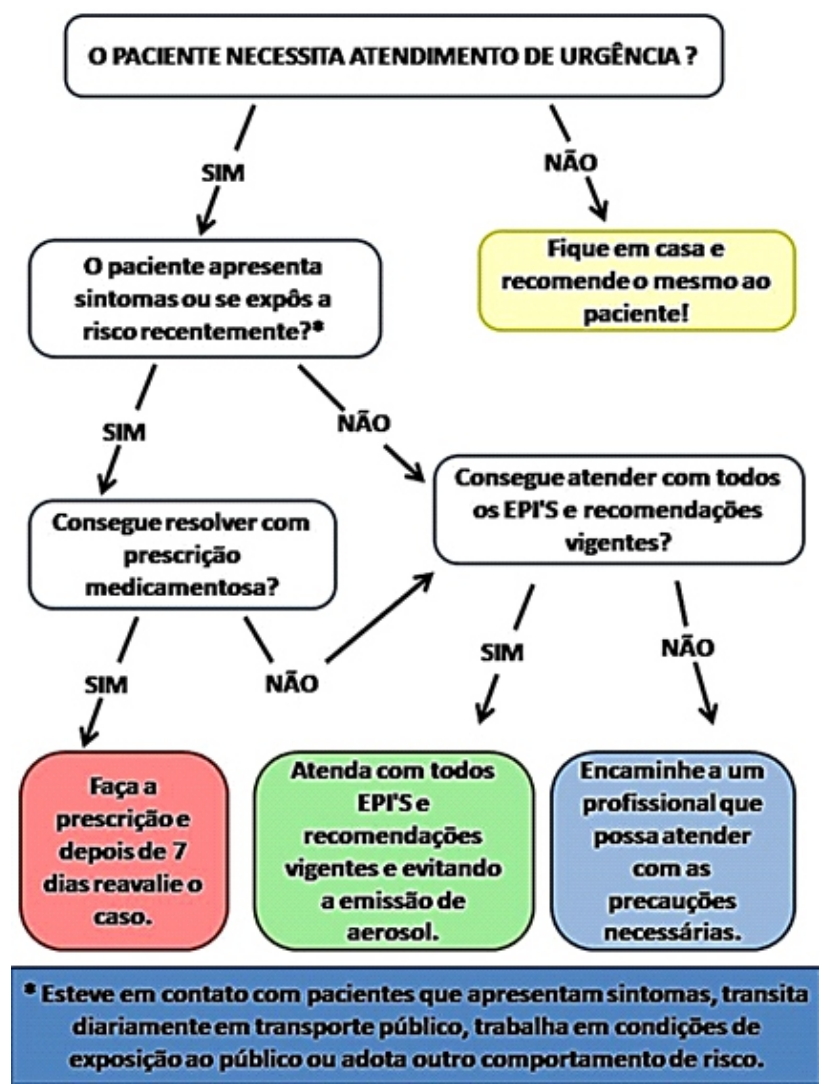

Figura 1 - Fluxograma da triagem do paciente.

Fonte: Adaptado de

http://cromg.org.br/wp-content/uploads/2020/04/A4FLUXOGRAMA-compactado.pdf.

As agências de saúde recomendam que o paciente sem suspeita de Covid-19, para tratamentos eletivos devem ser postergados, pacientes com suspeita da doença com tratamentos eletivos devem ser orientados a fazer isolamento domiciliar imediatamente por pelo menos 14 dias, procurar serviço de saúde somente em caso de agravamento dos sintomas e se abster de comparecer aos serviços odontológicos. Pacientes com sintomas de infecção respiratória ou febre só deverão ser tratados em caso de emergência ${ }^{7,14,17}$.

\section{Medidas de Prevenção}

São recomendados os motores com válvulas antiretração ou antirrefluxo, com o objetivo de impossibilitar a contaminação cruzada. Os motores que não possuem esse sistema podem aspirar e expelir os detritos e fluidos durante os procedimentos odontológicos, com o agravo dos microorganismos, incluindo bactérias e vírus, contaminarem ainda mais os tubos de ar e água na unidade odontológica e, 
portanto, tornarem-se agentes de infecção cruzada. Portanto, o uso de motores odontológicos sem função antiretração deve ser desaconselhado principalmente durante o período epidêmico do Covid- $19^{5,7}$.

Há estudos que relatam a sobrevivência do Covid-19 de dois a nove dias em superfícies. Por essa razão, todas as superfícies contaminadas por aerossóis ou contato direto devem ser desinfectadas, utilizando-se hipoclorito de sódio a $0.1 \%$, ou álcool a $70 \%$ e peróxido de hidrogênio a $0.5 \%$. É igualmente importante o uso de barreiras de proteção, as quais devem ser trocadas a cada paciente ${ }^{7}$.

Recomenda-se fazer o uso de tapete desinfetante bactericida na porta de entrada da clínica. Deve-se retirar da sala de espera todas as revistas e enfeites que possam viabilizar contaminação pelo manuseio e posterior toque nas mucosas do rosto. Sempre os pacientes e acompanhantes na sala de espera, devem se manter afastados, é de grande importância evitar aglomeração em ambientes de espera, mantendo um distanciamento entre as cadeiras de pelo menos 1 metro de distância, deve dispor de álcool a 70\% em gel e de orientações sobre a correta lavagem das mãos e sobre etiqueta respiratória para os pacientes ${ }^{7,13-14}$.

O consultório e todas as superfícies tocadas deverão ser desinfetadas rigorosamente, podendo ser usado álcool 70\%, hipoclorito de sódio a $0.1 \%$, ou peróxido de hidrogênio a $0.5 \%$. As barreiras de proteção devem ser trocadas a cada paciente, os materiais deverão ser esterilizados após sua utilização em autoclave e a manipulação de perfurocortantes devem ser realizadas cuidadosamente, para evitar acidentes e contaminação por esses instrumentos ou pelo contato direto entre membranas mucosas e mãos contaminadas ${ }^{13-14}$.

\section{Abordagem no Atendimento Odontológico}

Sabe-se que a aplicação prévia de bochechos antimicrobianos reduz o número de micro-organismos orais. No entanto, a clorexidina, comumente usada na prática odontológica, não apresenta eficácia contra o Covid-19. Como o coronavírus é vulnerável à oxidação, recomenda-se o uso de bochechos de peróxido de hidrogênio a $1 \%$ ou lodopovidona a $0.2 \%$, antes do procedimento realizado em ambulatório, para reduzir microrganismos intraorais ${ }^{5,7}$.

O uso de barragens de borracha para isolamento absoluto minimiza substancialmente a produção de aerossóis e respingos contaminados com sangue e saliva. Estudos indicam que a enzima conversora de angiotensina II (ECAII), presente também em tecidos orais, é um receptor da Covid-19, esses achados indicam que órgãos com células com alta expressão de ECAII devem ser considerados como de alto risco, como potencial reservatório de Covid-19 ${ }^{17-18}$. Quando, contudo, houver impossibilidade de isolar o campo dessa forma, deve-se eleger o TRA (Tratamento Restaurador Atraumático) para remoção manual de tecido cariado, além de raspagem manual, com o objetivo de mitigar a produção de aerossóis ${ }^{5,7}$.

\section{Urgência e Emergência Odontológica}

Mediante a situação de pandemia mundial, no dia 16 de março de 2020, o Conselho Federal de Odontologia, por meio do OFÍCIO n 477/2020, recomendou a suspensão das atividades odontológicas que não sejam comprovadamente de urgência e emergência no setor público ${ }^{19}$ (Tabela 1). Em relação ao setor privado, recomendou-se a observação das medidas de desinfecção, limpeza e dos protocolos de esterilização, de modo que sejam eliminadas ou minimizadas as chances de contágio ${ }^{14}$.

Tabela 1 - Tipos de tratamento odontológico.

\begin{tabular}{|c|c|c|c|}
\hline \multicolumn{4}{|c|}{ TIPOS DE TRATAMENTO ODONTOLÓGICO (ADA, 2020) } \\
\hline \multirow{2}{*}{\begin{tabular}{|c|} 
EMERGÉNCIA \\
$\begin{array}{c}\text { situasçes que potencializamo } \\
\text { nisco de monte ao paciente }\end{array}$ \\
\end{tabular}} & \multirow{2}{*}{\multicolumn{2}{|c|}{ 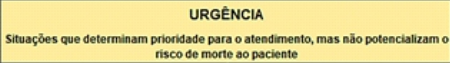 }} & \multirow{3}{*}{ 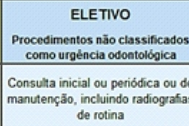 } \\
\hline & & & \\
\hline $\begin{array}{l}\text { Sangramentos näo } \\
\text { controlados }\end{array}$ & Remoçăo de suturas & $\begin{array}{l}\text { Biopsia de alteraçбes anormais dos } \\
\text { tecidos bucais }\end{array}$ & \\
\hline \multirow{3}{*}{ 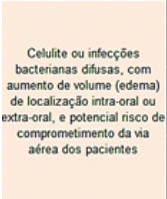 } & 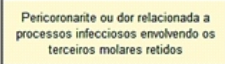 & $\begin{array}{l}\text { Tratamento odontológico necessảion } \\
\text { pretivio à procededimento médico crtico }\end{array}$ & $\begin{array}{l}\text { Profilaxias de rotina, ou } \\
\text { procedimentos com finalidade } \\
\text { preventiva ou estética }\end{array}$ \\
\hline & $\begin{array}{l}\text { Ameolite pós-operatátia, controle ou } \\
\text { aplicaçăo medicamentosa local }\end{array}$ & 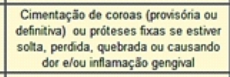 & \multirow{2}{*}{ 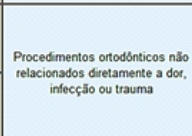 } \\
\hline & $\begin{array}{l}\text { Finalizaçălo ou troca para medicaçilo } \\
\text { intracanal para tratamentos } \\
\text { endodobnticos jai iniciados }\end{array}$ & $\begin{array}{l}\text { Mucosites orais com indicaçăo de } \\
\text { tratamento com laserereapia }\end{array}$ & \\
\hline \multirow{3}{*}{$\begin{array}{l}\text { Traumatismo emolvendo os } \\
\text { ossos da face, compotencial } \\
\text { comprometimento da via } \\
\text { aérea do paciente }\end{array}$} & 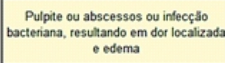 & $\begin{array}{l}\text { Ajuste, troca ou remoceso do arco ou } \\
\text { dispositivo ontodobntico que estiver } \\
\text { Ulicerando a mucosasa bucal }\end{array}$ & 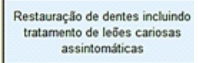 \\
\hline & 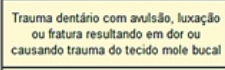 & $\begin{array}{l}\text { Ajuste ou reparo de próteses removiveis } \\
\text { que estejam causando dor ou com a } \\
\text { funçăbo mastigatória comprometica }\end{array}$ & \multirow{2}{*}{ 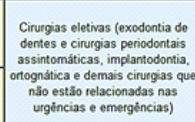 } \\
\hline & $\begin{array}{l}\text { Cshies extensas ou restauraçás com } \\
\text { problemas que estejam causando dor }\end{array}$ & $\begin{array}{l}\text { Nectoses orais com dor e presencha de } \\
\text { sectoçálo purvienta }\end{array}$ & \\
\hline
\end{tabular}

Fonte: Adaptado de

https://success.ada.org/ /media/CPS/Files/Open\%20Files/ADA _COVID19_Dental_Emergency_DDS.pdf

\section{Atendimentos em Unidade de Terapia Intensiva}

A necessidade de tratamento em unidade terapia intensiva (UTI), em pacientes infectados vem sendo um desafio a saúde pública. A odontologia já se faz presente em ambientes de UTI, desenvolvendo um controle para redução de patógenos orais, que podem levar a Pneumonia Associada à Ventilação Mecânica (PAVM), e diante da pandemia, esse cuidado se torna primordial. A saúde bucal contribui para a recuperação dos pacientes de forma integral, na UTI eles se encontram totalmente dependentes do suporte de profissionais da saúde, como o cirurgiãodentista para higienização bucal ${ }^{20}$. De acordo com a Anvisa $(2020)^{15}$, o protocolo de higienização oral frente a Covid19, continua com protocolo padrão em pacientes não acometidos, higienização com clorexidina $0.12 \%$, utilizando-se de gaze estéril para o procedimento que deve ocorrer pelo menos 2 vezes ao dia. Se paciente confirmado ou suspeito, o uso do mesmo produto se torna dispensável, onde a intervenção recomendada se dá pela higienização 
por 1 minuto, com peróxido de hidrogênio a $1 \%$, ou povidona $0.2 \%$, também embebidos em gaze estéril, com intuito de reduzir a carga viral.

\section{DISCUSSÃO}

O cirurgião-dentista possui um grande risco de exposição ao coronavírus, tendo-se em vista seu contato íntimo e constante com fluidos orgânicos e injúrias percutâneas dos pacientes. A Associação de Medicina Intensiva Brasileira assim como o Conselho Federal de Odontologia afirma que o profissional deve estar ciente e praticar os protocolos de biossegurança, implementando de forma rigorosa, medidas de controle de infecção no consultório odontológico com o objetivo de minimizar ou idealmente evitar a infecção no ambiente de trabalho. Além disso, deve ser capaz de identificar um caso suspeito de Covid-19 a partir de uma triagem inicial ${ }^{13-14}$.

Ainda declaram que o cirurgião-dentista e sua equipe devem estar sujeitos a avaliações constantes de saúde, nas quais haja aferição da temperatura corporal duas vezes ao dia, sendo uma antes do início dos atendimentos e a outra ao longo do dia, devendo ser afastado por 14 dias o membro da equipe que apresentar febre, ${ }^{7,13}$.

Estudo mostrou que as práticas de atendimento odontológico, invariavelmente, levam o cirurgião-dentista ao risco de infecção devido à natureza de seus procedimentos e o surto de Covid-19 é um alerta sobre a importância de ser diligentes na proteção contra a disseminação de doenças infecciosas ${ }^{8}$. Assim, como prestadores de serviços de saúde, o cirurgião-dentista deve ser cauteloso com a doença e saber como ela se propaga, como identificar pacientes infectados, quais as modificações precisam ser feitas na prática para evitar a transmissão da doença ${ }^{21}$.

$\mathrm{O}$ atendimento odontológico urgente aos pacientes e a preservação da saúde dos dentistas é fundamental para controlar a disseminação da doença e para a manutenção da saúde das pessoas em isolamento, confinamento ou quarentena, assim como para a atuação do próprio serviço de saúde ${ }^{22}$.

Dessa forma, devemos estar sempre cientes das ameaças que podem desafiar o regime de controle de infecções, principalmente nos consultórios odontológicos. Por isso, a busca por melhores estratégias de prevenção e controle de infecções ainda precisam ser mais discutidas e pesquisadas, principalmente diante de doenças contagiosas como o coronavírus e semelhantes ${ }^{2,20}$.

\section{CONCLUSÃO}

Foi possível concluir que o cirurgião-dentista deve estar ciente e praticar os protocolos de biossegurança, implementando de forma rigorosa, medidas de controle de infecção no consultório odontológico com o objetivo de minimizar ou idealmente evitar a infecção no ambiente de trabalho. Diante a essa pandemia, como profissional de saúde com possibilidade de exposição, é necessário prezar pela sua proteção, dos pacientes e toda sua equipe odontológica, buscando um ambiente seguro e que siga as diretrizes orientadas.

\section{REFERÊNCIAS}

1. Zhu N, Zhang D, Wang W, Li X, Yang B, Song J. A novel coronavirus from patients with pneumonia in China, 2019. N Engl J Med. 2020;382(8):727-33.

2. Meng L, Hua F, Bian Z. Coronavirus disease 2019: emerging and future challenges for dental and oral medicine. JDR. 2020;99(5):481-7.

3. Zhang W, Jiang X. Measures and suggestions for the prevention and control of the novel Coronavírus in dental institutions. Front Oral Maxillofac Med. 2020;2:1-4.

4. Brasil. Ministério da Saúde. Doença pelo novo coronavírus 2019 COVID-19 [Internet]. Brasília: Ministério da Saúde; 2020 [cited 2020 M a y 30 ]. A v a i 1 a b 1 e f r o m : https://portalarquivos2.saude.gov.br/images/pdf/2020/fevereiro/21/ 2020-02-21-Boletim-Epidemiologico03.pdf

5. Peng X, Xu X, Li Y, Cheng L, Zhou X, Ren B. Transmission routes of 2019-nCoV and controls in dental practice. Int J Oral Sci. 2020;12(9).

6. Sohrabi C, Alsafi Z, O'Neill N, Khan M, Kerwan A, Al-Jabir A, et al. World Health Organization declares global emergency: a review of the 2019 novel coronavirus (COVID-19). Int J Surg. 2020;76:71-6.

7. Tuñas ITC, Silva ET, Santiago SBS, Maia KD, Silva-Júnior GO. Doença pelo coronavírus 2019 (COVID-19): uma abordagem preventiva para odontologia. Rev Bras Odontol. 2020;77(1):1-6.

8. Sabino-Silva R, Jardim ACG, Siqueira WL. Coronavirus COVID-19 impacts to dentistry and potential salivary diagnosis. Clin Oral Investig. 2020;24(4):1619-21.

9. Wang Y, Wang Y, Chen Y, Qin Q. Unique epidemiological and clinical features of the emerging 2019 novel coronavirus pneumonia (COVID-19) implicate special control measures. J Med Virol. 2020;92(6):568-76.

10. Yu F, Du L, Ojicius DM, Pan C, Jiang S. Measures for diagnosing and treating infections by a novel coronavirus responsible for a pneumonia outbreak originating in Wuhan, China. Microbes Infect. 2020;22(2):74-9.

11. Guan WJ, Ni ZY, Hu Y, Liang WH, Ou CQ, He JX, et al. Clinical characteristics of coronavirus disease 2019 in China. N Engl J Med. 2020;382:1708-20. 
12. Li ZY, Meng LY. Prevention and control of new coronavirus infection in oral diagnosis and treatment. Chin J Stomatol. 2020,55(4):217-22.

13. Associação de Medicina Intensiva Brasileira. Recomendações AMIB para atendimento odontológico COVID-19 [Internet]. São Paulo: AMIB; 2020 [cited 2020 May 20]. Available from:https://www.amib.org.br/fileadmin/user_upload/amib/2020/m

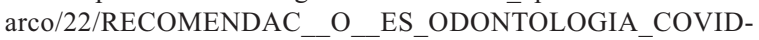
19_AMIB_-_2020_pdf_t_-p $\overline{\text { df }}$

14. Conselho Federal de Odontologia. Recomendações para atendimentos odontológicos em tempos de COVID-19 [Internet]. Brasília: CFO; 2020 [cited 2020 Apr 21]. Available from: http://website.cfo.org.br/wp-content/uploads/2020/03/MaterialCDs-Coronavi\%CC\%81rus-CFO-1.pdf

15. Brasil. Agência Nacional de Vigilância Sanitária [Internet]. Brasília: Anvisa; 2020 [cited 2020 May 30]. Available from:http://portal.anvisa.gov.br/documents/33852/271858/Nota+T \% C 3\% A 9 c n i c a + n + $04-2020+$ G V IM S - G G T E S ANVISA/ab598660-3de4-4f14-8e6f-b9341c196b28

16. Conselho Regional de Odontologia. Fluxograma para atendimentos odontológicos -COVID-19 [Internet]. Belo Horizonte: CROMG; 2020 [cited 2020 Apr 27]. Available from: http://cromg.org.br/wpcontent/uploads/2020/04/A4-FLUXOGRAMA-compactado.pdf

17. To KK-W, Tsang OT-Y, Yip CC-Y, Chan K-H, W T-C, Chan JM-C, et al. Consistent detection of 2019 novel coronavirus in saliva. Clin Infect Dis. 2020;71(15):841-3.

18. Xu H, Zhong L, Deng J, Peng J, Dan H, Zeng X, et al. High expression of ACE2 receptor of 2019-nCoV on the epithelial cells of oral mucosa. Int J Oral Sci. 2020;12(1):8.

19. American Dental Association [Internet]. Chicago: ADA; 2020 [cited 2020 A p r 21] . Ava i 1 a b 1 e fro m : https://success.ada.org/ /media/CPS/Files/Open\%20Files/ADA_C OVID19_Dental_Emergency_DDS.pdf?utm_source=adaorg\&utm _medium $=$ covid-resources-lp\&utm_content $=\mathrm{cv}$-pm-emerg$\overline{\mathrm{d}}$ e f \& u t m c a m p a $\overline{\mathrm{i}} \mathrm{g} \mathrm{n}=\mathrm{c}$ o v i d $19 \&$ \& a $=2.1587 \overline{1} 19422.527261862 .1584796909$ 1982106663.1584563184

20. Bellissimo-Rodrigues WT, Menegueti MG, Gaspar GG, Souza HCC, Auxiliadora-Martins M, Basile-Filho A, et al. Is it necessary to have a dentist within an intensive care unit team? Report of a randomised clinical trial. Int Dent J. 2018;68(6):420-7.

21. Samaranayake LP. Severe acute respiratory syndrome and dentistry: a retrospective view. J Am Dent Assoc. 2004;135(9):1292-302.

22. Jackson Filho JM, Assunção AA, Algranti E, Garcia EG, Saito AC, Maeno M. A saúde do trabalhador e o enfrentamento da COVID-19. Rev Bras Saude Ocup. 2020;45:1-3. 